

\section{DISCLAIMER}

This report was prepared as an account of work sponsored by an agency of the United States Government. Neither the United States Government nor any agency Thereof, nor any of their employees, makes any warranty, express or implied, or assumes any legal liability or responsibility for the accuracy, completeness, or usefulness of any information, apparatus, product, or process disclosed, or represents that its use would not infringe privately owned rights. Reference herein to any specific commercial product, process, or service by trade name, trademark, manufacturer, or otherwise does not necessarily constitute or imply its endorsement, recommendation, or favoring by the United States Government or any agency thereof. The views and opinions of authors expressed herein do not necessarily state or reflect those of the United States Government or any agency thereof. 


\section{DISCLAIMER}

Portions of this document may be illegible in electronic image products. Images are produced from the best available original document. 


\title{
TEST MASKS FOR THE EXPERIMENTAL EVALUATION OF AUTOMATED IC PHOTOMASK INSPECTION SYSTEMS*
}

\author{
D. R. Ciarlo
}

\section{ABSTRACT}

The design and fabrication of a test mask suitable for the experimental evaluation of automated IC photomask inspection systems is described. This mask contains various types and sizes of intentional defects in known locations. The defects are superimposed on a background of images consisting of a typical integrated circuit pattern.

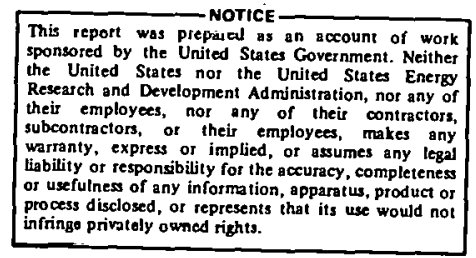

*This work was performed under the auspices of the U.S. Energy Research and Development Administration under contract number W-7405-ENG-48. 


\title{
TEST MASKS FOR THE EXPERIMENTAL EVALUATION OF AUTOMATED IC PHOTOMASK INSPECTION SYSTEMS
}

\author{
D. R. Ciarlo
}

INTRODUCTION

In an earlier report ${ }^{(1)}$ the technologies that could be used to automate the inspection of integrated circuit (IC) photomasks were analyzed. These technologies were divided into two major types. The first type includes those that use non-comparative inspection strategies such as TV-microscopes, microdensitometers, and single beam flying spot scanners. The second type includes those that use comparative inspection strategies such as dual beam flying spot scanners, optical comparators and spatial filtering systems. The following describes an inspection test mask that was designed to experimentally evaluate automated IC photomask inspection systems.

Several things need to be determined in the evaluation of an automated photomask inspection system. Among them are the following:

1. Minimum detectable defect si<e.

2. Speed.

3. Missed defects.

4. False indications.

5. Pinhole detection vs. opaque spot detection.

When an automated inspection system is in use, a test mask can be used to periodically insure that the detection threshold of the machine is appropriately set for the detection of the defects of interest.

\section{TEST MASK DESIGN}

A test mask designed to experimentally verify the sensitivity of an inspection system was described by Bruning, et. al. (2) Their mask contains both opaque and transparent defects of 1-10 $\mu \mathrm{m}$ size in known locations. It is used on a regular basis to verify the performance of their system. 
Other test masks have been described for use in various areas of the photolithographic process. For instance, H. R. Rottmann ${ }^{(3)}$ discusses a mask. that is used to test a step and repeat camera. J. J. Obzanski ${ }^{(4)}$ has proposed a mask to be used in a test of photoresist adhesion. Also, Goldrick and Plauger ${ }^{(5)}$ describe the use of a step tablet in the evaluation of photoresist exposure parameters. These are just some of the test masks used in the photolithographic process. However, only the one described by Bruning was designed to be used in the evaluation of an automated mask inspection system.

Several approaches can be used to design a test mask for automated mask inspection systems. It is not clear which approach is optimum. The mask described in this report was designed primarily to evaluate a systems capability to find visual defects rather than its capability to determine the dimensional accuracy of the line widths on the mask. The following ground rules were used.

1. A $21 / 2^{\prime \prime} \times 21 / 2^{\prime \prime} \times 0.6^{\prime \prime}$ substrate was used to minimize the run-out problems found with $4 " \times 4^{\prime \prime}$ substrates.

2. The intentional defects include round opaque spots, protrusions, bridges, round pinholes, intrusions and breaks.

3. The intentional defects are positioned in a random but known location throughout the mask.

4. The intentional defects are superimposed on a typical MOS metallization pattern.

5. A $150 \mathrm{mil}$ by 150 mil chip size is used.

6. A 14 by 14 array of die is stepped and repeated on the mask.

7. Of the 196 total die on the mask, approximately $8 \%$ (15) contain intentional defects. 
The $8 \%$ figure for the number of intentional defective die was chosen because this figure is often used to define a rejectable mask. ${ }^{(6)}$ These 15 defective die are inserted into the array by the use of three extra $10 x$ reticles as will be described later. Each of the three extra $10 x$ reticles contains a total of 36 defects that are intentionally inserted. Table I lists the types and sizes of the defects. The sizes listed are those that would occur on the $1 \times$ mask if there were no dimensional changes during the processing.steps used to make the mask. The actual dimensions on the mask that is delivered by the vendor must be determined by making measurements. On the first design of the test mask, the smallest defect size was designed to be $1.9 \mu \mathrm{m}$ so that there would be some chance of this defect actually printing on the mask.

TABLE I. INTENTIONAL DEFECTS ON THE "DEFECTIVE DIE"

\begin{tabular}{|c|c|c|c|}
\hline Type & Quantity & Size $(\mu \mathrm{m})$ & \\
\hline Pinholes & 14 & $7.6,6.4,5.1,3.8,2.8,2.5,1.9$. & (two each) \\
\hline Spots & 14 & $7.6,6.4,5.1,3.8,2.8,2.5,1.9$ & (two each) \\
\hline Breaks & 2 & 7.6 wide & \\
\hline Bridges & 2 & 7.6 wide & \\
\hline Intrusions & 2 & $\begin{array}{l}\text { Half way into a clear area. } \\
7.6 \text { wide }\end{array}$ & \\
\hline Protrusion & 2 & $\begin{array}{l}\text { Half way into an opaque line. } \\
7.6 \text { wide }\end{array}$ & \\
\hline $\begin{array}{l}\text { Total per } \\
10 x \text { reticle }\end{array}$ & 36 & & \\
\hline
\end{tabular}

The unusual sizes for the defects are caused by the available aperture sizes used in the artwork generating equipment. All the pinholes and opaque spots are round. The actual number of intentional defects represents a compromise between the need for a large number in order to get good statistics on an inspection system and the desire to hold the number down so as to simplify the mask fabrication process. 
Each of the three "defective" $10 x$ reticles is stepped into the array in five different places so that the total number of intentional defects on the mask is:

$$
3 \times 5 \times 36=540 \text { intentional defects. }
$$

The 15 defective die are inserted into the array in more or less random locations.

Figure 1 illustrates the basic MOS metallization pattern used to make up each die. The smallest line widths or spaces in this pattern are 0.3 mils $(7.62 \mu \mathrm{m})$. The width of the pattern is $10.5 \mathrm{mi} / \mathrm{s}(0.27 \mathrm{~mm})$ and the height is $7.8 \mathrm{mils}(0.20 \mathrm{~mm})$. Each die consists of a 10 by 10 array of this basic pattern with a center to center spacing in the $y$-direction of 12 mils $(0.30 \mathrm{~mm})$ and a center to center spacing in the $x$-direction of $10 \mathrm{mils}(0.25 \mathrm{~mm})$ as shown in Figure 2. In order to identify the location of the intentional defects, the basic patterns in each die are identified by two numbers as indicated in Figure 2. The first number indicates the row and the second number indicates the column with the numbering system origin at the upper left hand corner of the mask when it is viewed with the opaque coating up and with the basic pattern oriented as shown in Figure 2 .

The final mask consists of a 14 by 14 array of die as illustrated in Figure 3. Again the die are identified by a numbering system similar to the system used to identify the basic patterns within each die. The center to center spacing of the die is $150 \mathrm{mils}(3.81 \mathrm{~mm})$ in each direction. An area of $28.5 \mathrm{~cm}^{2}$ is covered by this 14 by 14 array which leads to a defect density of $540 / 28.5=19 \mathrm{~cm}^{-2}$. Of the 196 total die in the array, 15 .contain intentional defects. Figure 3 illustrates the position of these 15 "defective die" by the numerals II, III, and IV. Reticle number I is assumed to be perfect.

\section{TEST MASK FABRICATION}

The first test mask was fabricated using artwork generated at LLL. An 
independent mask vendor generated the $10 x$ reticle and stepped the array on a $21 / 2^{\prime \prime}$ by $21 / 2^{\prime \prime}$ photoplate. This mask is designated ITM which stands for Inspection Test Mask. The following is the sequence of events.

1. The background pattern for the inspection test mask is the metallization layer of a PMOS metal gate R-S flip-flop. This pattern was chosen because of its level of complexity. It was felt that a background pattern consisting of a dense pattern of images would provide the most useful evaluation of an automated defect inspection system. The pattern is stored in the memory of an interactive graphical display system (IGDS) at LLL. A hard copy printout of the background pattern is shown in Figure 4. The interactive graphical display system generates the commands required to drive a photoplotting system that draws the image of one die at $200 x$ actual size.

2. The photoplotting system is used to draw four copies of the image of one die each at 200x. One of these copies is not altered. Intentional defects are added to the other three in known locations. The added defects include bridges, protrusions, and opaque spots as indicated in Table I. Figure 5 shows examples of the added defects. The location of the intentional defects within the three "defective die" is given in Table II. Also included in the 200x artwork are registration targets on both sides of the 10 by 10 array of basic patterns separated by 32 inches. These targets are separated by 1.6 inches in the $10 x$ reticle which is required to align the reticle in the step and repeat camera.

3. The 200x photoplots are contact printed to arrive at a dark field copy. Intentional defects are again added to the three dark field copies that already contain the defects printed by the photoplotting system. These new defects will eventually become breaks, intrusions, and pinholes. They are added to the 200x artwork with tape as illustrated in Figure 6 . Figure 7 . shows examples of the added defects. Again, their location is given in Table II. 
TABLE II LOCATION OF THE INTENTIONAL DEFECTS.

ON THE DEFECTIVE DIE

\begin{tabular}{|c|c|c|c|}
\hline Broken Image & $\begin{array}{r}\text { Reticle II } \\
(5,4) \\
(8,8) \\
\end{array}$ & $\begin{array}{c}\text { Reticle III } \\
(6,1) \\
(0,1)\end{array}$ & $\begin{array}{c}\text { Reticle IV } \\
(1,9) \\
(2,5) \\
\end{array}$ \\
\hline Intrusion & $\begin{array}{l}(9,3) \\
(3,2) \\
\end{array}$ & $\begin{array}{l}(4,5) \\
(6,2) \\
\end{array}$ & $\begin{array}{l}(0,0) \\
(6,5) \\
\end{array}$ \\
\hline Protrusion & $\begin{array}{l}(9,7) \\
(2,3)\end{array}$ & $\begin{array}{l}(8,1) \\
(0,9)\end{array}$ & $\begin{array}{l}(4,4) \\
(2,0)\end{array}$ \\
\hline Bridge & $\begin{array}{l}(5,3) \\
(0,7) \\
\end{array}$ & $\begin{array}{l}(9,9) \\
(2,1) \\
\end{array}$ & $\begin{array}{l}(6,8) \\
(0,4)\end{array}$ \\
\hline $7.6 \mu \mathrm{m} \mathrm{Spot}$ & $\begin{array}{l}(6,4) \\
(4,0)\end{array}$ & $\begin{array}{l}(9,6) \\
(0,6)\end{array}$ & $\begin{array}{l}(0,9) \\
(3,6)\end{array}$ \\
\hline 6.4 & $\begin{array}{l}(7,4) \\
(4,8)\end{array}$ & $\begin{array}{l}(7,0) \\
(1,6)\end{array}$ & $\begin{array}{l}(8,6) \\
(1,3)\end{array}$ \\
\hline 5.1 & $\begin{array}{l}(7,1) \\
(1,9)\end{array}$ & $\begin{array}{l}(6,7) \\
(4,3)\end{array}$ & $\begin{array}{l}(8,3) \\
(4,7)\end{array}$ \\
\hline 3.8 & $\begin{array}{l}(1,0) \\
(0,5)\end{array}$ & $\begin{array}{l}(2,9) \\
(9,5)\end{array}$ & $\begin{array}{l}(8,9) \\
(4,2)\end{array}$ \\
\hline 2.8 & $\begin{array}{l}(8,5) \\
(0,2)\end{array}$ & $\begin{array}{l}(7,5) \\
(0,3)\end{array}$ & $\begin{array}{l}(5,1) \\
(9,2)\end{array}$ \\
\hline 2.5 & $\begin{array}{l}(2,8) \\
(7,3)\end{array}$ & $\begin{array}{l}(8,4) \\
(2,4)\end{array}$ & $\begin{array}{l}(9,8) \\
(1,1)\end{array}$ \\
\hline 1.9 & $\begin{array}{l}(8,0) \\
(1,4) \\
\end{array}$ & $\begin{array}{l}(3,7) \\
(1,2)\end{array}$ & $\begin{array}{l}(9,4) \\
(3,1)\end{array}$ \\
\hline $7.6 \mu \mathrm{m}$ pinhole & $\begin{array}{l}(7,9) \\
(3,4)\end{array}$ & $\begin{array}{l}(3,0) \\
(0,8)\end{array}$ & $\begin{array}{l}(7,2) \\
(1,7)\end{array}$ \\
\hline 6.4 & $\begin{array}{l}(9,1) \\
(4,6)\end{array}$ & $\begin{array}{l}(8,7) \\
(5,0) \\
\end{array}$ & $\begin{array}{l}(2,7) \\
(1,2)\end{array}$ \\
\hline$\overline{5.1}$ & $\begin{array}{l}(7,6) \\
(5,9)\end{array}$ & $\begin{array}{l}(4,1) \\
(1,5)\end{array}$ & $\begin{array}{l}(5,6) \\
(6,0)\end{array}$ \\
\hline 3.8 & $\begin{array}{l}(5,2) \\
(2,6)\end{array}$ & $\begin{array}{l}(7,8) \\
(3,3)\end{array}$ & $\begin{array}{l}(7,7) \\
(3,8) \\
\end{array}$ \\
\hline 2.8 & $\begin{array}{l}(3,9) \\
(3,5)\end{array}$ & $\begin{array}{l}(6,9) \\
(6,6) \\
\end{array}$ & $\begin{array}{l}(5,5) \\
(6,3)\end{array}$ \\
\hline 2.5 & $\begin{array}{l}(4,9) \\
(5,7) \\
\end{array}$ & $\begin{array}{l}(5,8) \\
(8,2)\end{array}$ & $\begin{array}{l}(9,3) \\
(0,8)\end{array}$ \\
\hline 1.9 & $\begin{array}{l}(6,0) \\
(4,9)\end{array}$ & $\begin{array}{l}(0,5) \\
(0,0)\end{array}$ & $\begin{array}{l}(9,7) \\
(0,2)\end{array}$ \\
\hline
\end{tabular}


4. The four pieces of artwork are again contact printed to arrive at a clear field version. Any unwanted clear areas, especially those caused by the edges of the transparent tape used to add defects, are opaqued.

5. The artwork is again contact printed to arrive at the dark field version preferred by the mask maker.

6. Four clear field $10 x$ reticles are made, one for each piece of $200 x$ artwork using a 20x photo-reduction. Each $10 x$ reticle is on an emulison photoplate and is clear field.

7. Each of the four 10x reticles is contact printed onto a chromium photoplate using positive photoresist to give a clear field, hard surface, 10x reticle. (This step happens to be unique to the mask vendor doing the work.)

8. The "defect free" $10 x$ reticle, call it reticle \#I, is stepped and repeated onto a $21 / 2^{\prime \prime}$ by $21 / 2^{\prime \prime}$ chromium photoplate using positive photoresist to form the clear field master mask at 1x. Places for the insertions, as indicated in Figure 3, are left blank.

9. "Defective" 10x reticles \#II, \#III, and \#IV are sequentially put into the step and repeat camera and inserted into the array as indicated in Figure 3.

10. The master photomask is contact printed onto a chromium photoplate and an iron-oxide photoplate using positive photoresist to arrive at the two masks delivered by the mask vendor.

As might be expected, the cost of fabricating the master mask was the most expensive part of the test mask fabrication. Copies can be made of the master mask for approximately one-tenth its cost. Here are typical prices for the fabrication of the $21 / 2^{\prime \prime}$ by $21 / 2^{\prime \prime}$ inspection test mask starting from $200 x$ dark field artwork. 
Three extra 10x reticles for the inserts -..........- $\$ 105.00$ Contact print four emulsion $10 x$ reticles onto

four hard-surface photoplates--.-- 160.00

Basic hard-surface master made with reticle \#I-_-_._-_.-.-.-. 275.00

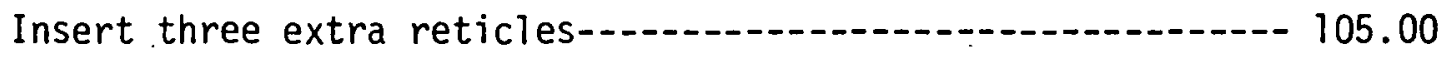

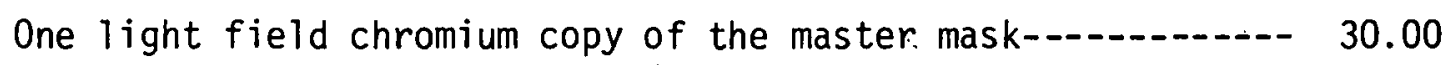

One light field iron-oxide copy of the master mask---.-- 30.00

TOTAL $\$ 705.00$

\section{IEST MASK EVALUATION}

Upon receiving the two masks, they were inspected manually under a microscope. A 56x objective was used having a numerical aperture of 0.90 . This was combined with a $10 x$ eyepiece. Very few, but some unintentional defects were found. An exact number for the unintentional defects cannot be given because only portions of the mask were scanned. Actually, the biggest problem with the masks as far as defects are concerned appeared to be unremoved photoresist which could probably be removed with a more thorough cleaning.

A careful inspection was made of the two smallest sized defects on the masks. As indicated in Table I, these should be circular defects with a diameter of $2.5 \mu \mathrm{m}$ and $1.9 \mu \mathrm{m}$. However, the mask vendor was told to optimize his process for the 0.3 mil minimum.line width on the basic pattern. Because of this, the dimensions of the smallest two defects are not equal to the design dimensions. Most likely the other defects also have dimensions that are different from the design dimensions. However, only the two smallest defects were inspected. The following is a summary of the inspection.

1.0 Chromium Mask

Each "defective" reticle inserted into the array contains two opaque spots and two pinholes of the sizes listed in Table 1. Since each reticle is inserted into the array five times, there should be 10 pinholes of each size from each reticle and the same number for the opaque spots. Table IIII gives the number of pinholes and opaque spots actually found by inspection. 
TABLE III SUMMARY OF THE SMALLEST PINHOLES AND SPOTS FOUND ON THE CHROMIUM TEST MASK*

\begin{tabular}{c|c|c|c|c} 
& $\begin{array}{l}1.9 \mu \mathrm{m} \\
\text { Pinhole }\end{array}$ & $\begin{array}{l}1.9 \mu \mathrm{m} \\
\text { Spot }\end{array}$ & $\begin{array}{l}2.5 \mu \mathrm{m} \\
\text { Pinhole }\end{array}$ & $\begin{array}{l}2.5 \mu \mathrm{m} \\
\text { Spot }\end{array}$ \\
\hline Reticle II & 5 & 4 & 10 & 10 \\
\hline Reticle III & 5 & 0 & 10 & 10 \\
\hline Reticle IV & 0 & 4 & 10 & 10 \\
\hline Total & 10 & 8 & 30 & 30
\end{tabular}

*The dimensions given are the design dimensions not the measured dimensions.

\subsection{Iron-0xide Mask}

The design of the iron-oxide mask is identical to the design of the chromium mask. In fact it is made by a contact print of the same master mask. So, there should be a total of 30 of each size pinhole and spot. Table IV shows what was found when a search was made for the smallest two sizes of pinholes and spots.

TABLE IV SUMMARY OF THE SMALLEST PINHOLES AND SPOTS FOUND ON THE IRON-OXIDE TEST MASK**

\begin{tabular}{c|c|c|c|c|} 
& $\begin{array}{l}1.9 \mu \mathrm{m} \\
\text { Pinholes }\end{array}$ & $\begin{array}{l}1.9 \mu \mathrm{m} \\
\text { Spot }\end{array}$ & $\begin{array}{l}2.5 \mu \mathrm{m} \\
\text { Pinhole }\end{array}$ & $\begin{array}{l}2.5 \mu \mathrm{m} \\
\text { Spot }\end{array}$ \\
\hline Reticle II & 0 & 10 & 10 & 10 \\
\hline Reticle III & 5 & 10 & 10 & 10 \\
\hline Reticle IV & 0 & 10 & 10 & 10 \\
\hline Total & 5 & 30 & 30 & 30 \\
\hline
\end{tabular}

$\star \star T h e$ dimensions given are the design dimensions not the measured dimensions. 


\subsection{Dimensional Inspection of the Chromium Test Mask}

The critical dimension tolerance used by the mask vendor on the smallest 1 ine width in the basic pattern was $0.3 \pm 0.020 \mathrm{mils}$. Measurements were made on the mask using image shearing line width measurement apparatus on a microscope with a $40 x$ objective $(N A=0.85)$ and a $16 x$ eyepiece. The mask was measured near its four corners and near the center on die that were made from reticle \#I. Measurements were also made on the die made from reticles \#II, \#III, and \#IV. In each case the 1 ine measured was positioned in the $(0,9)$ location of the 10 by 10 array of basic patterns making up the die. The actual line in the basic pattern that was measured is identified in Figure 8. Table $V$ gives the results of the measurements.

TABLE $V$ CRITICAL DIMENSION MEASUREMENTS ON THE CHROMIUM INSPECTION TEST MASK

\begin{tabular}{l||l}
$\begin{array}{l}\text { Reticle \& } \\
\text { location }\end{array}$ & $\begin{array}{l}\text { Measurement } \\
(\mu \text { in })\end{array}$ \\
\hline$I(3,12)$ & 301 \\
\hline$I(3,3)$ & 303 \\
\hline$I(12,3)$ & 301 \\
\hline$I(12,12)$ & 299 \\
\hline$I(7,7)$ & 300 \\
\hline$I I(6,7)$ & 302 \\
\hline$I I I(8,8)$ & 302 \\
\hline$I V(9,9)$ & 298 \\
\hline
\end{tabular}

As can be seen from Table $V$, the biggest deviation of the measured 1 ine width from the $300 \mu$ in designed width is $3 \mu$ in which is we 11 within the $\pm_{20}$ uin tolerance used by the mask vendor.

Some attempts were made to measure the diameter of the inserted defects. The defect with a designed diameter of $1.9 \mu \mathrm{m}$ was not measured because it did not print in many places as can be seen from Tables III \& IV. Also wherever this defect did print, it 
appeared to be much smaller than $1.9 \mu \mathrm{m}$. Measurements on the $2.5 \mu \mathrm{m}$ defects are summarized in Table VI. These measurements were made by photographing the area containing the defect and then scaling its dimension in comparison to a known line width nearby.

TABLE VI MEASURED DIAMETER OF THE DEFECTS DESIGNED TO BE $2.5 \mu \mathrm{m}$

\begin{tabular}{l|c|c} 
& Pinhole & Spot \\
\hline Chromium & 2.2 & 1.8 \\
\hline Iron-0xide & 2.8 & 1.9 \\
\hline
\end{tabular}

These measurements were made on only one defect of each type on the chromium mask and on the iron-oxide mask. As can be seen from Table VI, even though most of the $1.9 \mu \mathrm{m}$ defects did not print, this size defect is still available on the mask because of process induced dimensional changes on the $2.5 \mu \mathrm{m}$ defect.

The only serious problem with the Inspection Test Masks is the existence of scribe marks between the die as shown in Figure 10. There is a chance that the scribe marks around the inserted die are in a slightiy different position than those around the die printed using reticle \#I. Ordinarily, this difference would not matter. However, it would show up as an error when using an automated inspection system. For this reason, a new set of test masks has been ordered that do not contain the scribe marks.

\section{$\underline{\text { DISCUSSION }}$}

The fabrication of inspection test masks represents a task that is somewhat different from the job of making a standard integrated circuit mask especially because of the intentionally inserted defects. For this reason it is important to communicate closely with the technical staff of the mask vendor so that there is no misunderstanding about what is needed. Most mask vendors will quote a delivery time for a job like this of 3-4 weeks starting from the 200x artwork. Often there is a comprable delay in the processing of the purchase order. 
Once the mask is received, it is a tedious job to manually inspect it. As a matter of fact, it is practical only to verify that all the intentional defects did print. A complete inspection for all of the unintentional defects is best accomplished in cooperation with the owners and operators of existing automated defect inspection equipment. Throughout any inspection, care must be taken not to induce additional defects or not to contaminate the mask during the handling that is required.

This mask is primarily for the evaluation of a systems ability to inspect a mask for visual defects. However, defect inspection systems require that the dimensions on a mask be held to a certain tolerance. Some systems require a closer tolerance than others. So, the mask must be carefully measured before it can be used in a defect inspection machine. One of the more important measurements is the stepping distance between die. This distance must be within $\pm 20 \mu$ in throughout the mask. Since there are many inserts used, it is questionable that this tolerance can be maintained.

The first test mask that was built, (ITM), is now being measured. If it is found that the dimensions are outside of the required tolerances, two remedies can be tried. First, the master mask can be made using a laser metered step and repeat camera that has a quoted accuracy of $\pm 15 \mu \mathrm{in}$. Second, a pattern generator can be used to generate the $10 x$ relicie in hopes of eliminating any shrinkage seen with the $200 x$ artwork.

The size of the intentional defects must also be measured since anyone using the masks will want to know the smallest defect that their machine will detect. Those dimensions given in Table VI are of questionable accuracy since they were scaled from a photograph where edge positions are difficult to locate. Also, the numbers in Table VI represent only one pinhole and one spot on masks that contain a total of 420 such defects. It will probably be sufficient to measure only the three smallest size pinholes and spots since those that are larger will probably be very close to the designed dimension as was the $0.3 \mathrm{mil}$ mask critical dimension. Unfortunately, the four smallest pinholes and 
spots, those that are smaller than $4 \mu \mathrm{m}$, are difficult to measure with an image shearing eyepiece because at this dimension it becomes increasingly difficult to know exactly when the shear is complete.

Several copies of the inspection test mask will be required once it is found to be dimensionally correct. Two methods can be used to make these copies. One is to step several new master masks. The other is to contact print the present master as was done with the existing ITM. Wiley $(7)$ has reported that the first method, stepping original masters onto hard surface plates, results in a defect density of $1 / \mathrm{in}^{2}$. The second method, contact printing an original master results in a defect density of $6 / i^{2}$. These defect densities must be considered against the cost of stepping a new master $(\$ 380.00)$ versus making a contact print of an existing master $(\$ 30.00)$. Regardless of the method used to make copies, any new mask must be checked to see that the dimensions are within the required tolerances.

Once the inspection test masks are received and approved for use, they will be sent to companies with automated inspection systems. A description of the type and location of the intentional defects will also be sent. Mask making personnel at three different companies have already agreed to cooperate. They will determine how many of the intentional defects their systems find and how many unintentional defects are present. This data will more thoroughly describe the test masks so that in the future if someone is interested in testing an automated photomask inspection system they will have an appropriate set of test masks to use. 


\section{REFERENCES}

1. D. R. Ciarlo and P. A. Schultz, "Automated IC Photomask Inspection," to be published.

2. J. H. Bruning, et. al., "An Automated Mask Inspection System AMIS," IEEE Transactions on Electron Devices, Vol. ED-22, No. 7, July 1975, p. 487.

3. H. R. Rottmann, "Advances in Contact and Proximity Printing," Proceedings of the Kodak Microelectronics Seminar, 0ct. 21-22, 1974, San Diego, CA, p. 79.

4. J. J. Obzansky, Discussed at the ASTM Meeting, Gaithersburg, MD, June 10-12, 1975, Committee. F1.5.3.

5. M. R. Goldrick and L. R. Plauger, "Evaluation of Exposure Parameters for Photoresist Materials," Photographic Science and Engineer, Vol. 17, No. 4, July/August 1973, pp. 386-389.

6. J. Conroy, "Applications of Probability to Quantity Photomask Populations," Proceedings of the Kodak Microelectronics Seminar, October 29-30, 1973, Atlanta, Georgia, pp. 8-12.

7. J. Wiley, Presented at the Microphotomask/Masking Working Group Meeting, September 23, 1975 on "A Technological Comparison of. Photomasks," Hewlett Packard Auditorium, Santa Clara, CA. 


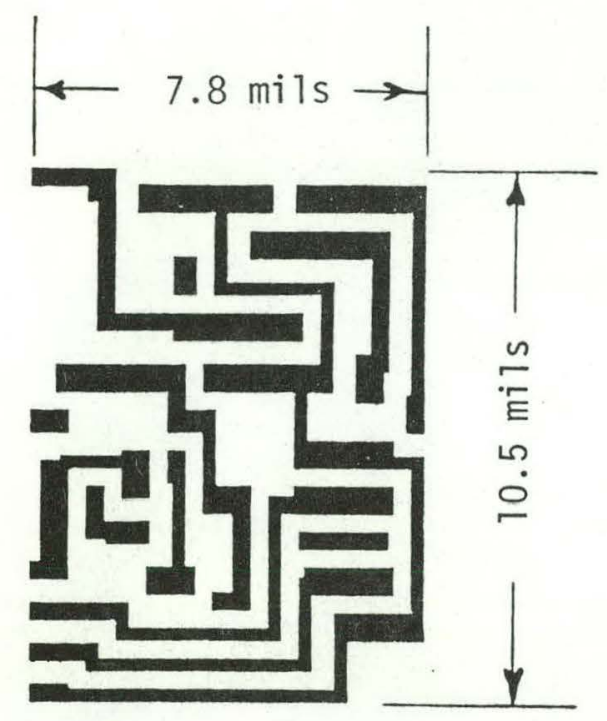

Fig. 1 Basic MOS metallization pattern used to make up each die. The minimum line width is $0.3 \mathrm{mils}$. The orientation applies when the mask is viewed with its opaque coating toward the viewer.

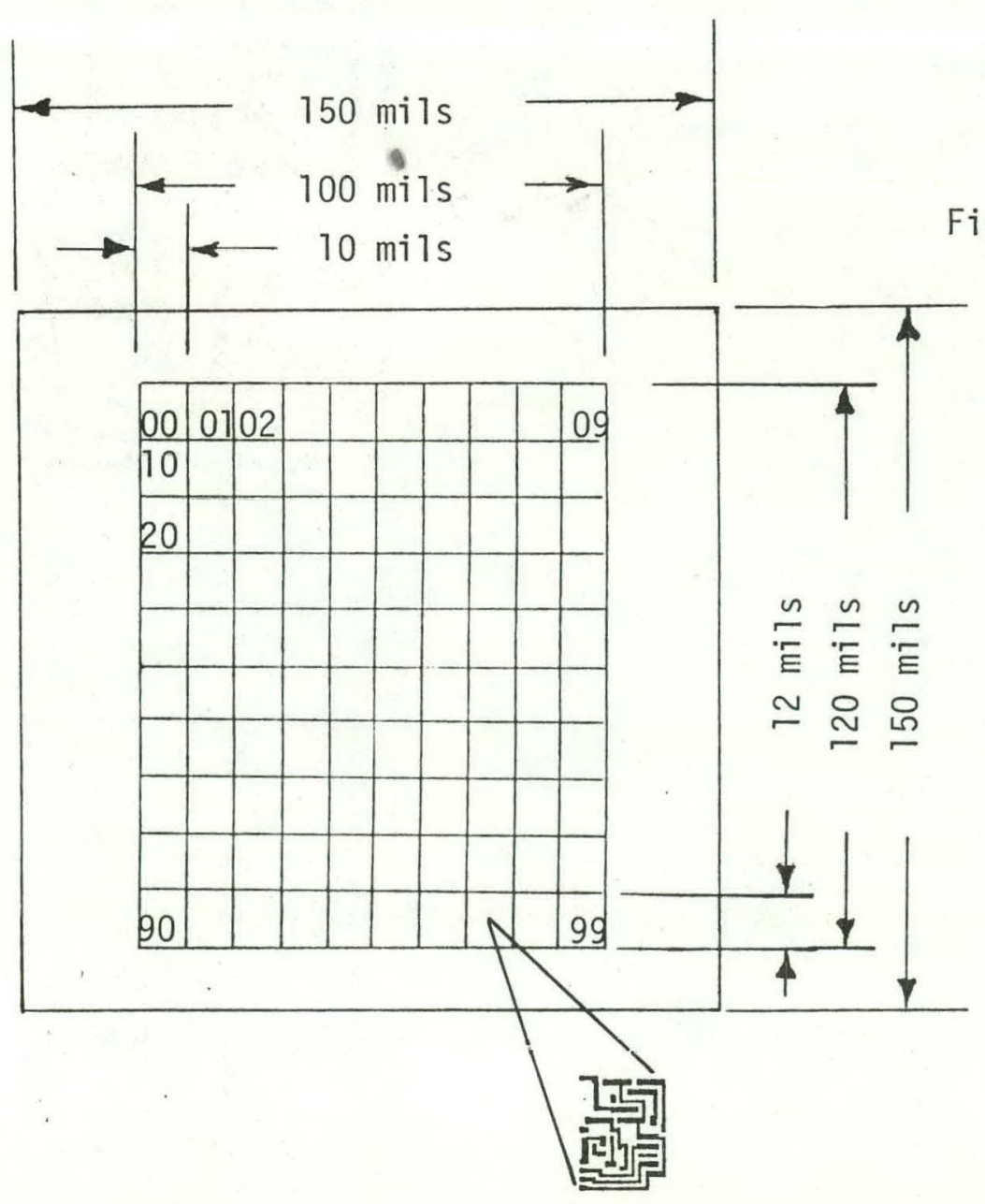

Fig. 2 One die consisting of a 10 by 10 array of the basic pattern shown in Fig. 1. The numbers within the die are used to locate the intentional defects. 


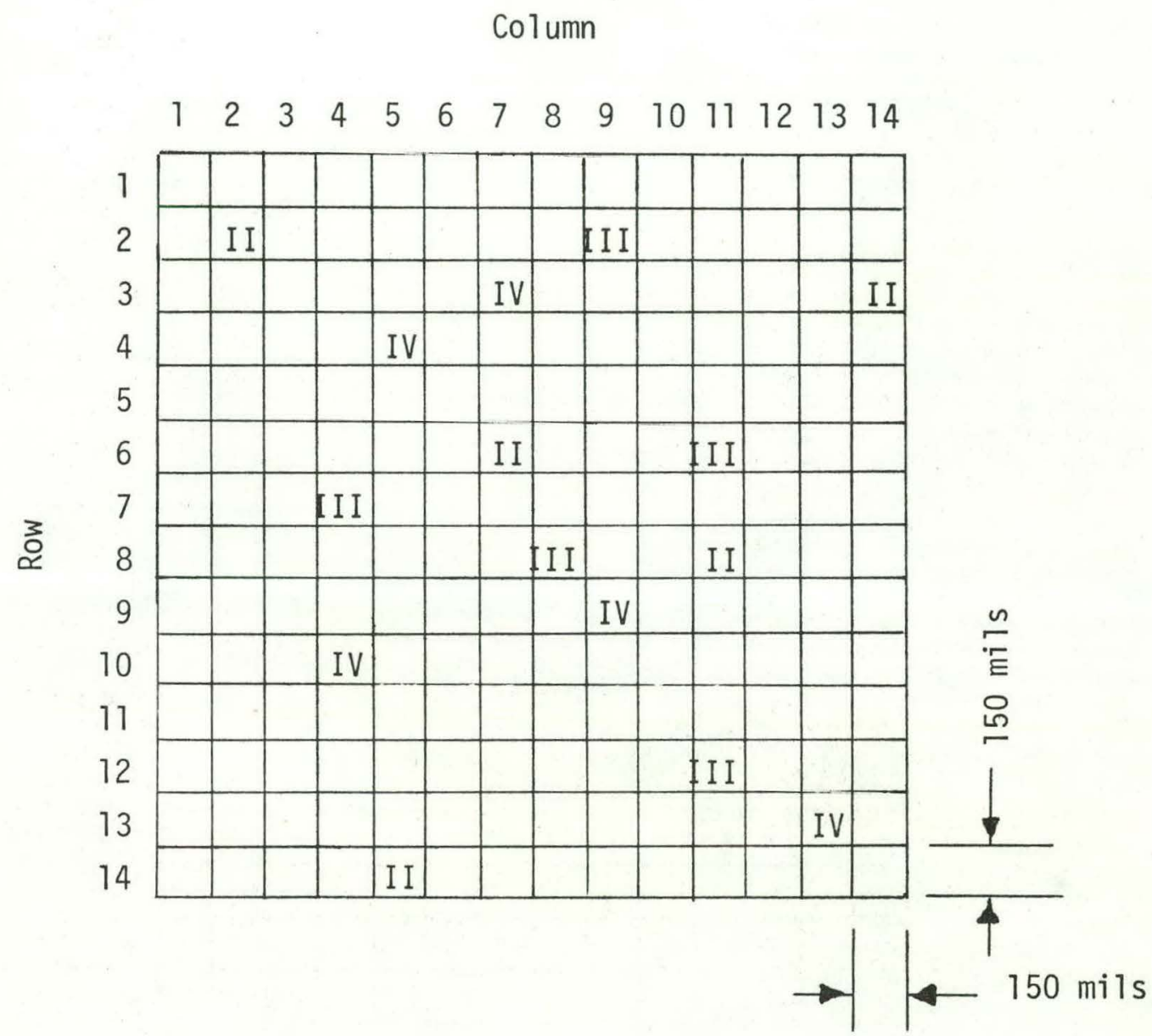

Fig. 3 Final 14 by 14 array of the die shown in Fig. 2. The numerals give the insert positions for the "defective" die. 


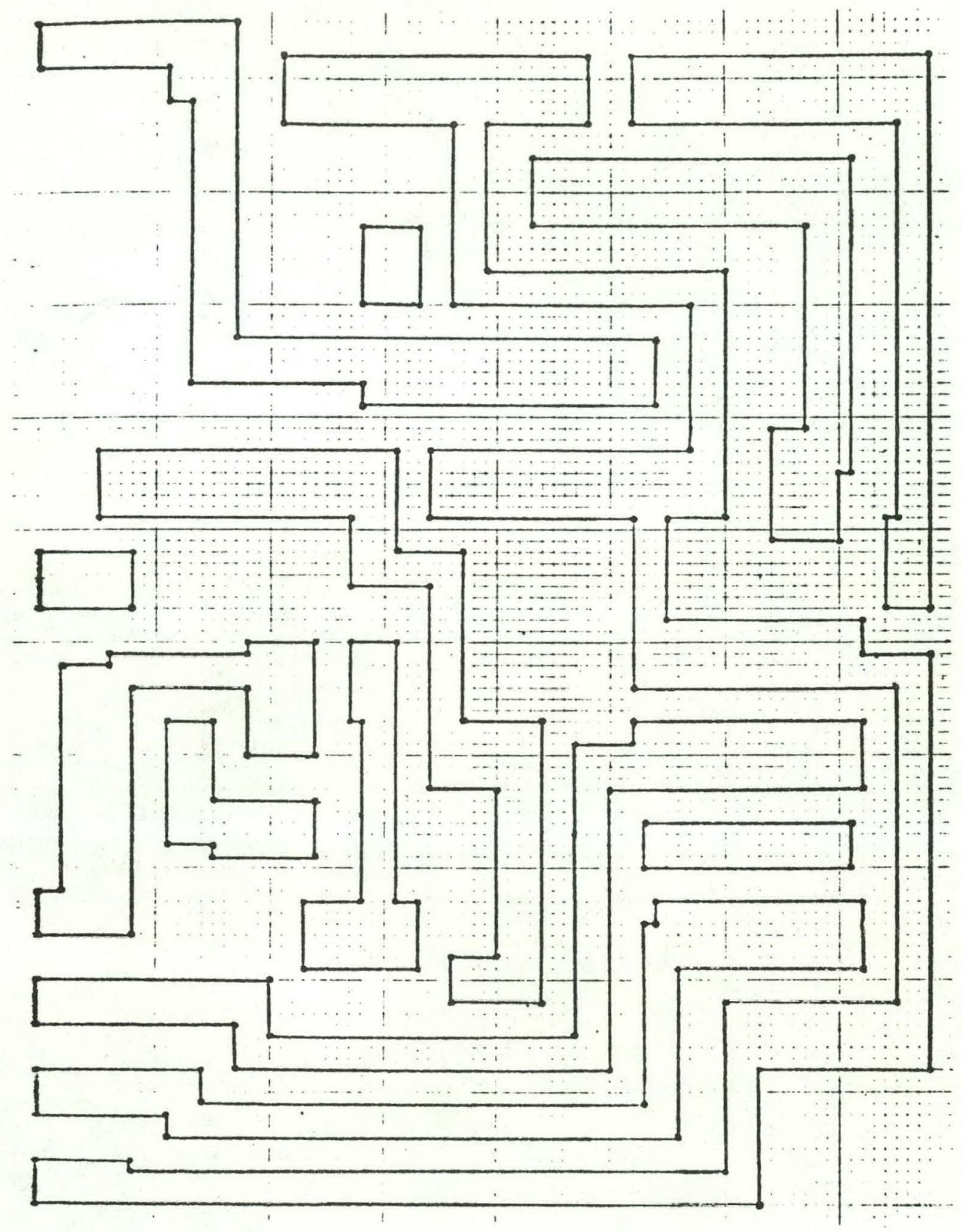

Figure 4 Printout of the background pattern stored in the IGDS. 

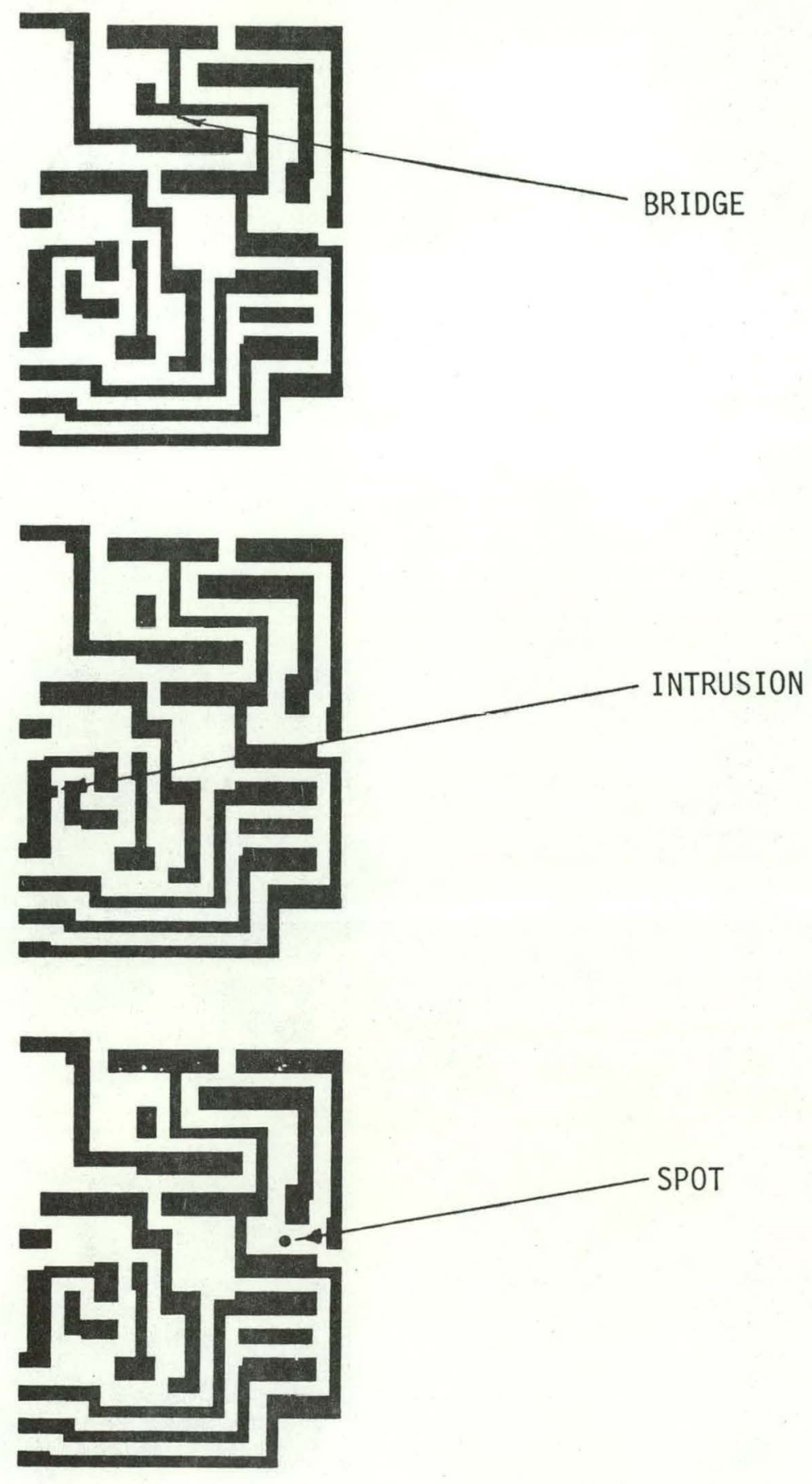

Figure 5 Examples of intentional defects added with the photoplotter. 


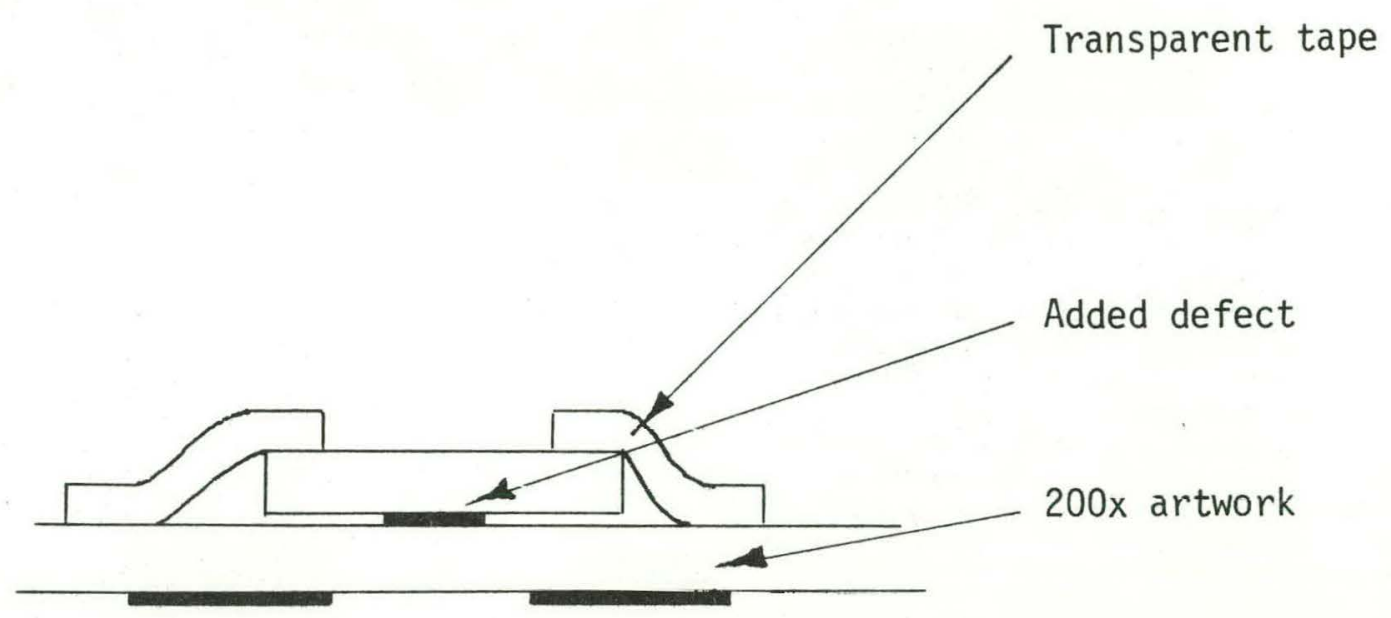

Figure 6 Illustration of how intentional defects are added to the 200x dark field artwork. 

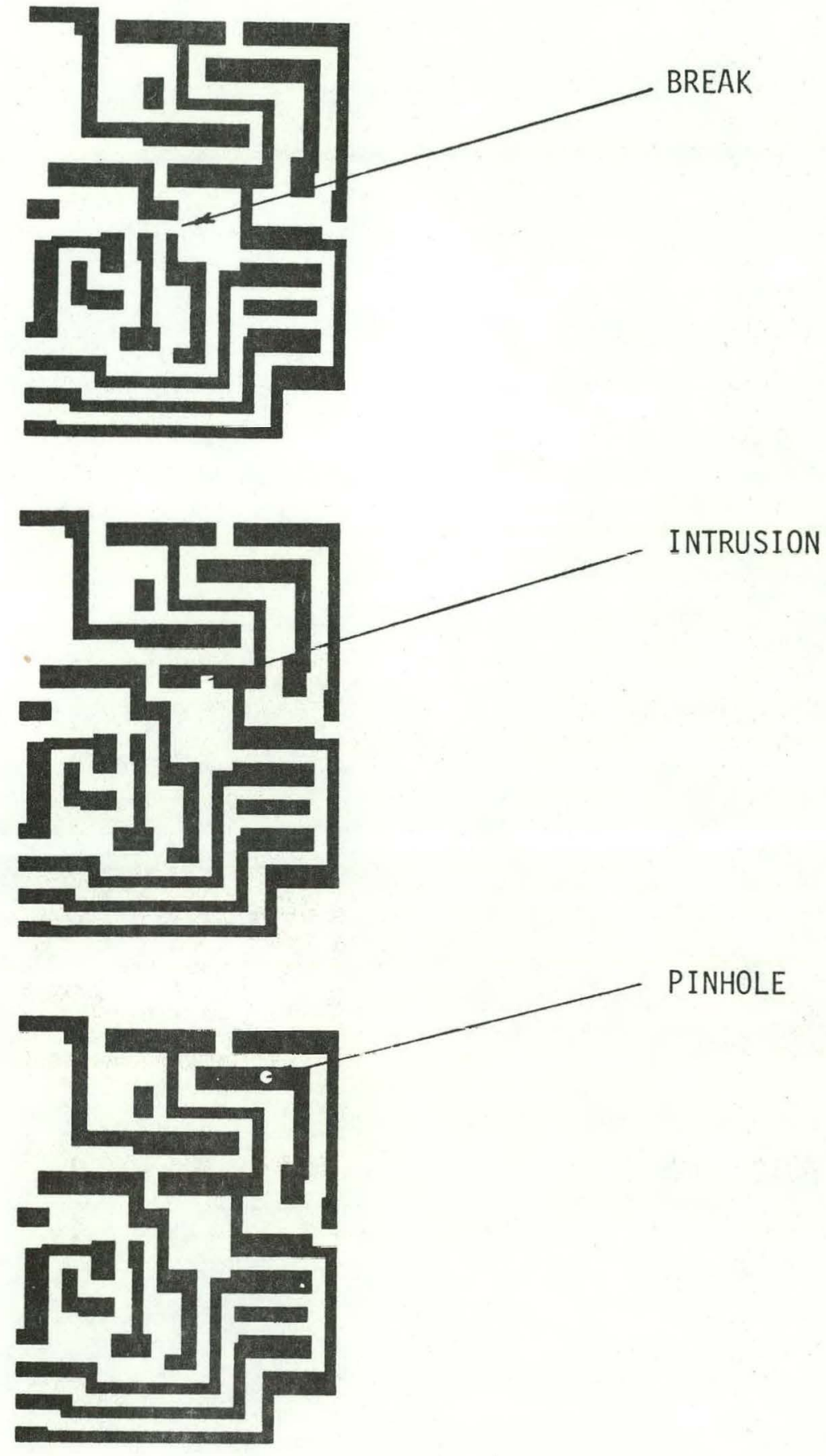

Figure 7 Examples of intentional defects added to the 200x artwork. 


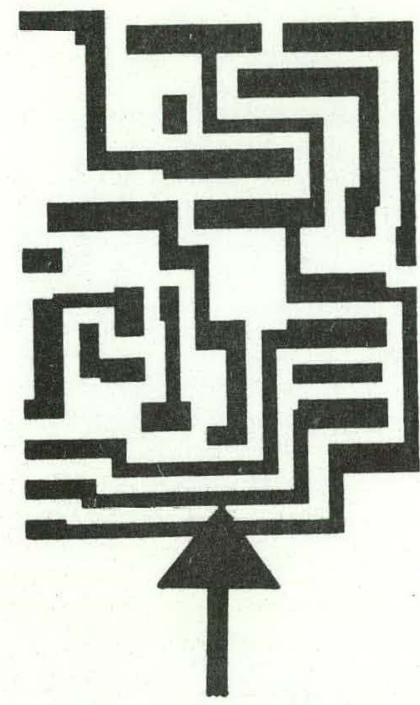

Figure 8 Location of the $0.3 \mathrm{mil}$ critical dimension measurement.
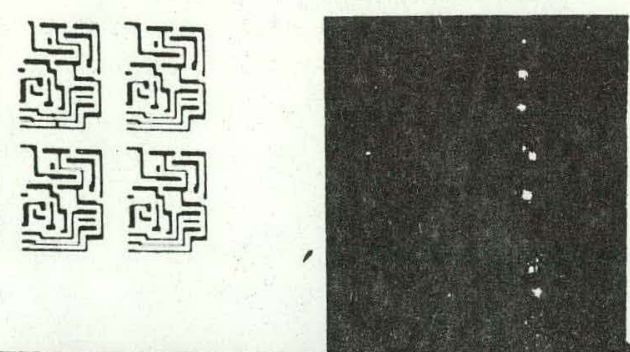

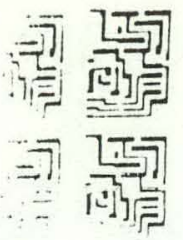

Figure 9 Scribe marks between die that could be a source for errors.

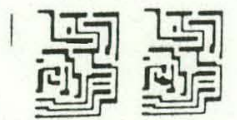

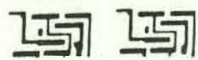

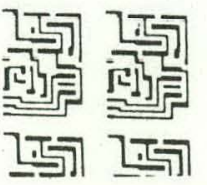


DISTRIBUTION :
D. R. Ciarlo
$L-156$
L. L. Cleland
$L-156$
W. C. Herrmann
$\mathrm{L}-15$
R. Kalibjian
$L-156$
E. A. Lafranchi
$L-151$
H. C. McDonald
$L-161$
P. A. Schultz
$L-151$
ERD File
$L-156$

(10)

(2)

D. B. Novotny

National Bureau of Standards

Washington, D.C. 20234

R. L. Raybold

National Bureau of Standards

Washington, D.C. 20234

TID, L-9

TIC, Oak Ridge, TN.

Printed in the United States of America Available from

National Technical Information Service

U.S. Department of Commerce

5285 Port Royal Road

Springfield, VA 22161

Price: Printed Copy $\$$; Microfiche $\$ 2.25$

\begin{tabular}{|c|c|c|c|}
\hline Page Range & $\begin{array}{c}\text { Domostic } \\
\text { Price } \\
\end{array}$ & Page Range & $\begin{array}{c}\text { Domestic } \\
\text { Price } \\
\end{array}$ \\
\hline $001-025$ & $\$ 3.50$ & $326-350$ & 10.00 \\
\hline $026-050$ & 4.00 & $351-375$ & 10.50 \\
\hline $051-075$ & 4.50 & $376-400$ & 10.75 \\
\hline $076-100$ & 5.00 & $401-425$ & 11.00 \\
\hline $101-125$ & 5.25 & $426-450$ & 11.75 \\
\hline $126-150$ & 5.50 & $451-475$ & 12.00 \\
\hline $151-175$ & 6.00 & $476-500$ & 12.50 \\
\hline $176-200$ & 7.50 & $501-525$ & 12.7 .5 \\
\hline $201-225$ & 7.75 & $526-550$ & 13.00 \\
\hline $226-250$ & 8.00 & $551-575$ & 13.50 \\
\hline $251-275$ & 9.00 & $576-600$ & 13.75 \\
\hline $276-300$ & 9.2 .5 & 601 -up & $*$ \\
\hline $301-325$ & 9.75 & & \\
\hline
\end{tabular}

"Add $\$ 2.50$ for each additional 100 page increment from 601 to 1,000 pages: add $\$ 4.50$ for each additional 100 page increment over 1,000 pages.

NOTICE

"This report was prepared as an account of work sponsored by the United Slates Government. Neither the United States nor the United States Energy Research \& Development Administration, nor any of their employees, nor any of their contractors, subcontractors, or their employees, makes any warranty, express of implicd, or assumes any legal liability or responsibility for the accuracy, completeness or usefulness of any information, apparatus, product or process disclosed, or represents that its use would not infringe privately-owned rights." 
Technical Information Department

LAWRENCE LIVERMORE LABORATORY

University of California | Livermore, California | 94550 